\title{
Amplified Fragment Length Polymorphism Fingerprinting to Identify Genetic Relatedness among Lychee Cultivars and Markers Associated with Small-seeded Cultivars
}

\author{
Ashish K. Pathak, Sudhir P. Singh ${ }^{1}$, and Rakesh Tuli \\ National Agri-Food Biotechnology Institute, Department of Biotechnology, C-127, Industrial Area, \\ Phase VIII, Mohali, India-160071
}

\begin{abstract}
ADDITIONAL INDEX wORDS. Litchi chinensis, polymorphic markers, pulp:seed ratio, small seed
Abstract. Amplified fragment length polymorphism (AFLP) was used to assess genetic relatedness among 23 popular commercial cultivars of lychee (Litchi chinensis) and identify the markers associated with small-seeded cultivars. A combination of three primer pairs with high discriminatory ability was selected for resolving the identity of lychee cultivars. The marker system resolved the instances of synonymies and homonymies. The two cultivars, Dehrarose and Dehradun, whose names are often used interchangeably, could be discriminated by AFLP. A cultivar, Calcuttia $(H)$, grown in the Punjab region was found genetically very similar to China (M) of Bihar region in India, suggesting that both could be the same clone. A number of cultivars with contrasting seed size were included in the study. The cultivars Bedana, Seedless Late, and China were positioned in one group, unlike the grouping previously reported based on morphological traits. The AFLP fingerprinting revealed five marker fragments exclusive to the genotypes, which bear fruit with small seed and large pulp.
\end{abstract}

Lychee is a subtropical evergreen fruit tree of family Sapindaceae (soapberry) and subfamily Nepheleae. The edible portion (aril) of the non-climacteric lychee fruit has a sweet and acidic taste, which makes it delicious and popular. The commercial lychee (Litchi chinensis ssp. chinensis) is native of southern China and northern Vietnam (Huang et al., 2005). China, India, Vietnam, Taiwan, Thailand, Madagascar, Nepal, Bangladesh, South Africa, Australia, Indonesia, Israel, Philippines, and the United States are the major centers for production (Diczbalis, 2011; Singh et al., 2012b). India ranks second, after China, in the production of lychee fruit, with $\approx 84,000$ ha area under lychee cultivation (Huang et al., 2005; National Horticulture Board, 2013).

China has the oldest history of lychee cultivation; the first reference dates back to 200 BCE in Hainain, Guangdong, and Guangxi (Huang et al., 2005). More than 200 cultivars or lines have been identified in China, although only 15 are widely cultivated commercially (Viruel and Hormaza, 2004). Lychee was introduced to India in the 18th century through Burma (Singh and Babita, 2002). Nearly 40 cultivars of lychee are grown, although only eight are commercially significant (Singh et al., 2012b). Fruit shape, skin protuberance, seed shape, leaf shape, flushing pattern, flush color, and flowering time are used to distinguish lychee cultivars. Based on the morphological

\footnotetext{
Received for publication 18 July 2014. Accepted for publication 9 Sept. 2014 The work is supported by National Agri-Food Biotechnology Institute, Department of Biotechnology (DBT), Government of India.

We gratefully acknowledge the Director, National Research Centre for Litchi (ICAR, Muzaffarpur, Bihar), Director, Fruit Research Station (PAU, Hoshiarpur, Punjab), and In-charge, Yadvendra Garden (Horticulture plot, Pinjore, Haryana) for providing leaf samples of lychee cultivars. The help of Swadha Singh (University of Allahabad) is cordially acknowledged in statistical analysis. A.K.P. acknowledges D.B.T. for providing fellowship.

${ }^{1}$ Corresponding author. E-mail: pratapsudhir17@gmail.com; sudhirsingh@nabi.
} res.in. traits, the Indian cultivars have been categorized in five groups (Table 1) (Dwivedi and Mitra, 1996; Singh and Babita, 2002). Some of the cultivars bear distinctly small to rudimentary seed and larger flesh. The morphological features are affected by climate and soil conditions, and this sometimes causes confusion in naming the cultivars (Degani et al., 2003; Huang et al., 2005). Seedlings of certain cultivars are morphologically similar and thus are often misidentified. The dissemination of lychee cultivars in neighboring states further adds to such confusion (Degani et al., 2003). It is, therefore, important to know genetic diversity in lychee and standardize identification of the cultivars. This is required for germplasm management and accelerated breeding programs. Attempts have been made to fingerprint and classify lychee cultivars using isozymes (Aradhya et al., 1995; Degani et al., 1995) and DNA polymorphism using random amplified polymorphic DNA [RAPD (Anuntalabhochai et al., 2002; Chundet et al., 2007; Kumar et al., 2010; Tongpamnak et al., 2002)], simple sequence repeat [SSR (Madhou et al., 2013; Mingfang et al., 2006; Sima et al., 2005; Viruel and Hormaza, 2004)], intersimple sequence repeat [ISSR (Degani et al., 2003)], and AFLP (Ganjun et al., 2003; Tongpamnak et al., 2002). Three studies have included Indian lychee cultivars in the molecular analysis, using ISSR (Degani et al., 2003), SSR (Madhou et al., 2013), and RAPD (Kumar et al., 2010) markers. Unlike many other genotyping techniques, AFLP offers genome-wide and easily reproducible screening of genetic diversity without the knowledge of genome sequence (Blignaut et al., 2013; Jones et al., 1997; Vuylsteke et al., 2007). An AFLP-dominant marker system has been established as a promising alternative to codominant markers such as SSRs and single nucleotide polymorphisms (Belaj et al., 2003; Campbell et al., 2003; Gerber et al., 2000; Jones et al., 1997; Meudt and Clarke, 2007; Schlotterer, 2004; Sunnucks 2000). The multiallelic microsatellite loci are highly informative with high discriminating capacity, whereas the 


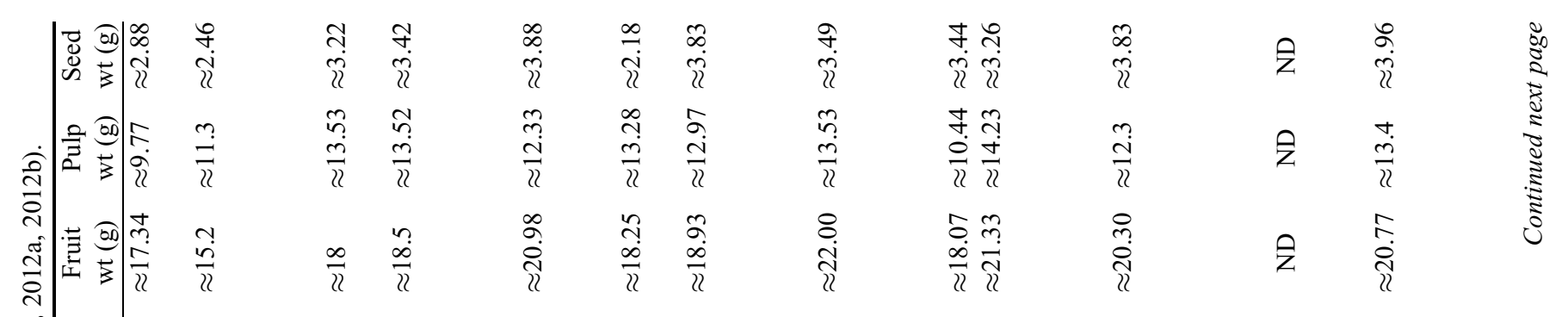

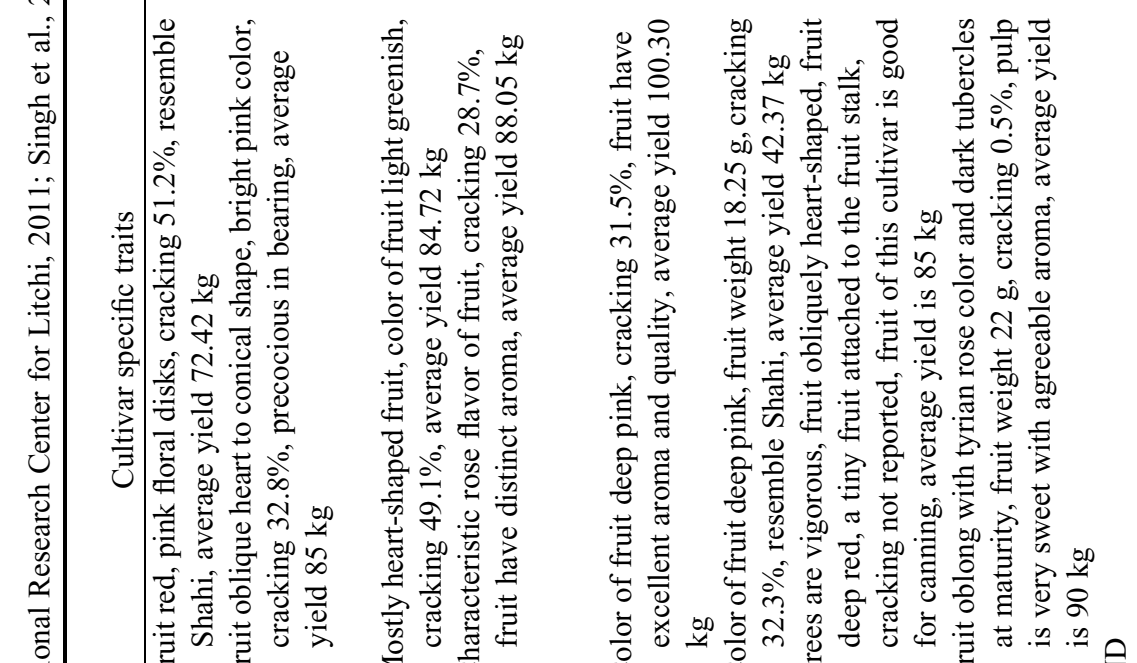

:

总

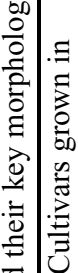

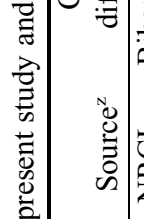

$\frac{2}{2}$

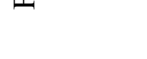

童意

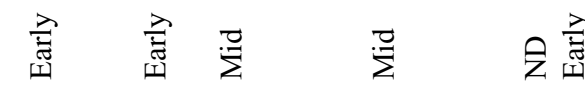

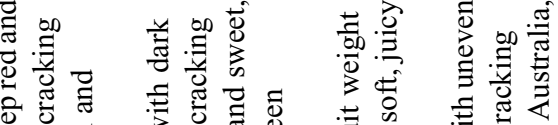

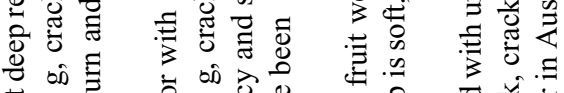

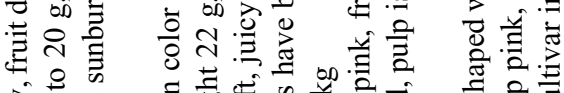

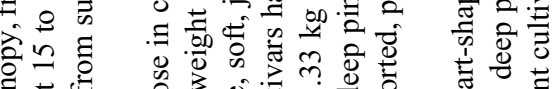

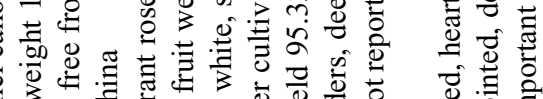

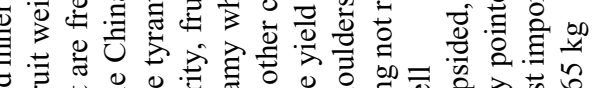

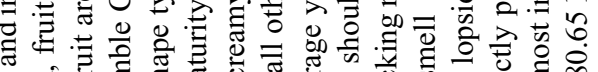

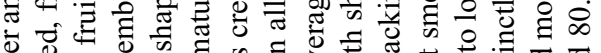

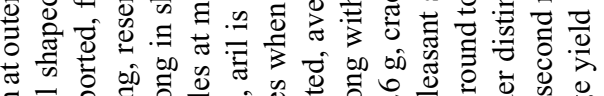

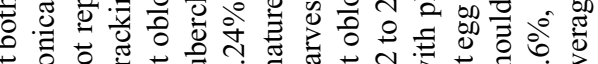

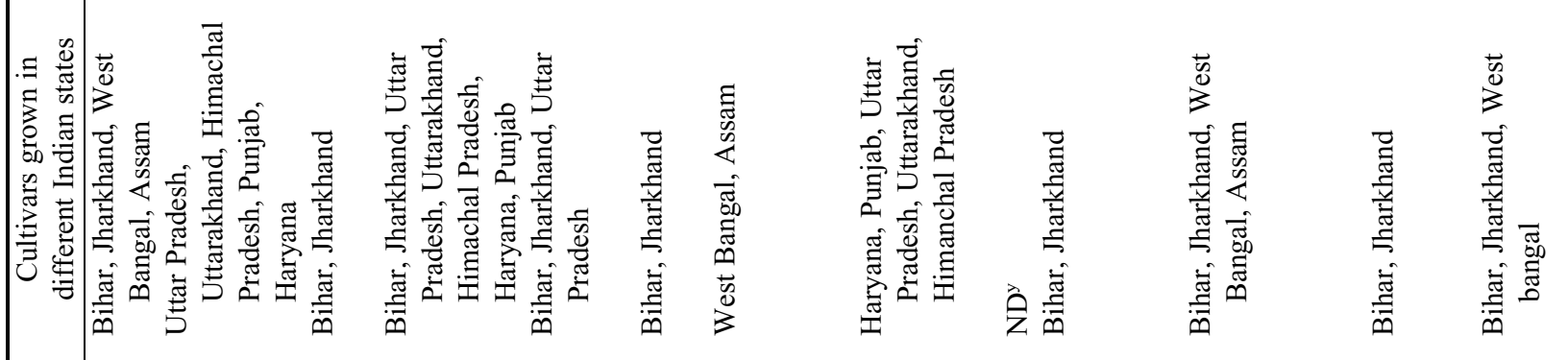

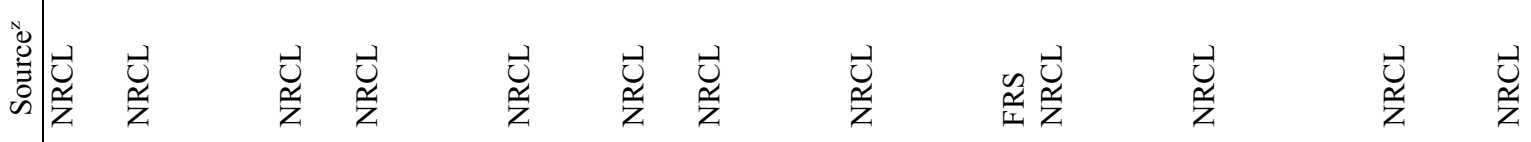

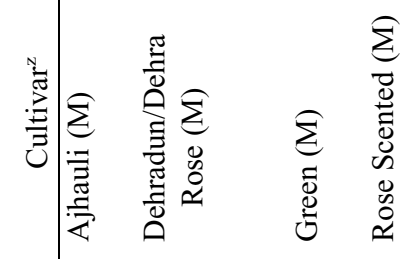

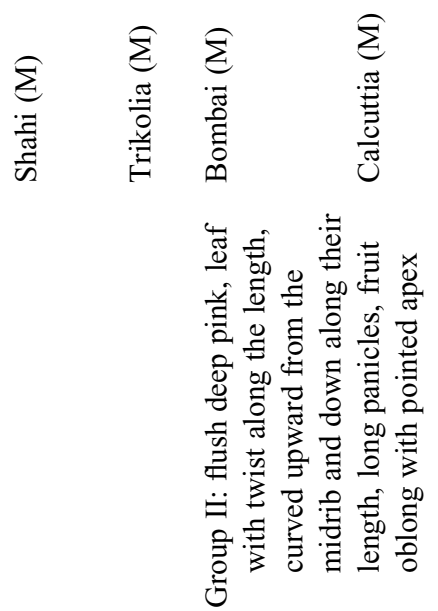




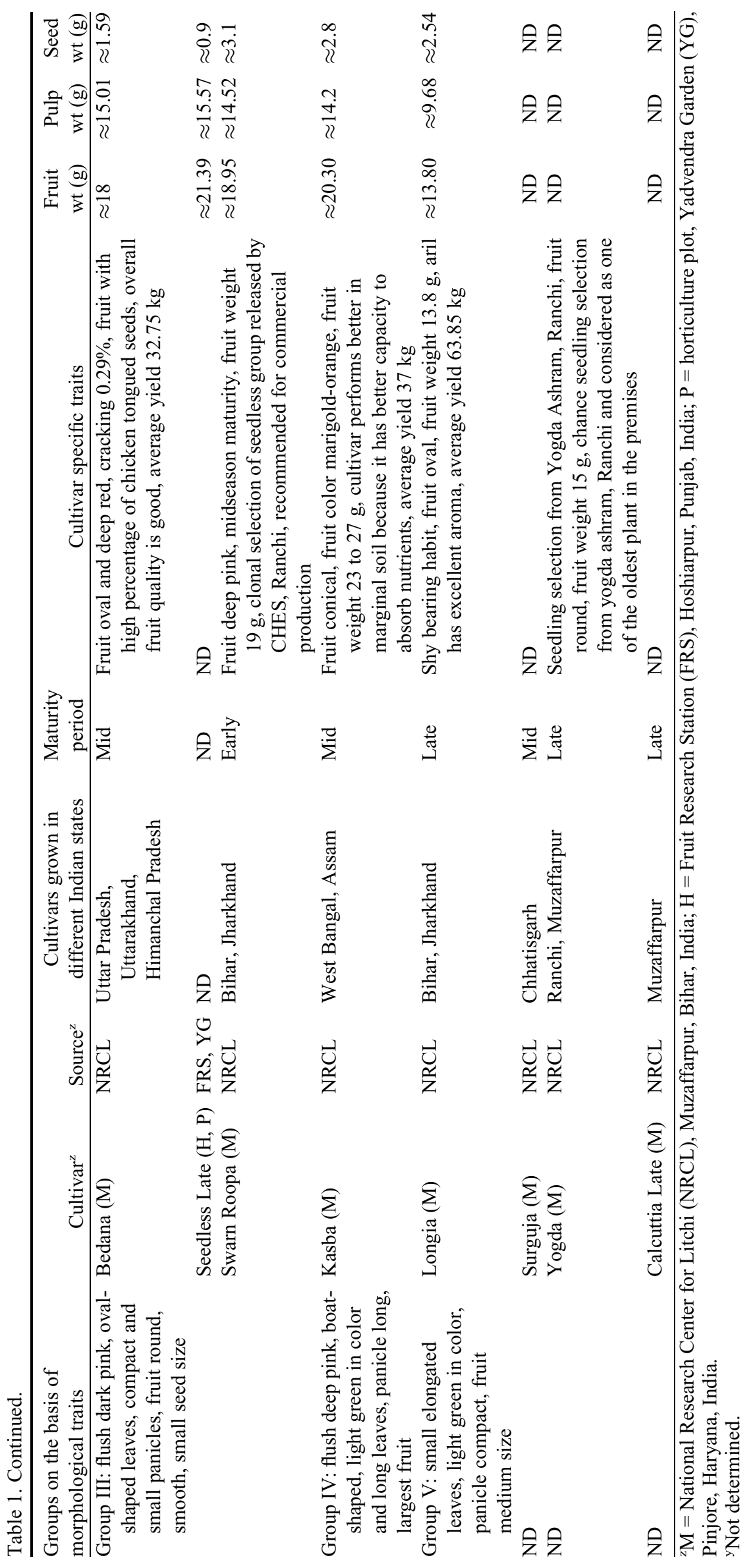


genome-wide di-allelic AFLP loci derive their statistical power from their sheer number (Belaj et al., 2003; Mariette et al., 2002; Sunnucks, 2000). In some of the studies that examined relative use of microsatellites and AFLPs in plants, congruent results were obtained with the two techniques (Woodhead et al., 2005). In few of the studies, AFLP was found to outperform microsatellites for genetic differentiation and thus can sometimes be more informative (Barbosa et al., 2003; Campbell et al., 2003; Jones et al., 1997; Kremer et al., 2005; Mariette et al., 2002; Perseguini et al., 2011; Woodhead et al., 2005). In addition, AFLP has been suggested as a preferred technique for detecting relationships among closely related cultivars (Guo et al., 2005).

The aim of the present study was to elucidate molecular diversity among the elite lychee cultivars grown in India. We used three primer combinations (EcoRI-AAC/MseI-CTG, EcoRI-ACC/MseI-CAT, and EcoRI-AGC/MseI-CAT) for the characterization of 23 Indian lychee cultivars. In a previous study, the primers had been identified as polymorphic for the analysis of genetic diversity among Chinese lychee cultivars (Ganjun et al., 2003). The genotyping data, presented in our study, evaluate suitability of the AFLP marker system in establishing genetic relationships among lychee cultivars and identified unique fragments associated with the cultivars with small seed size and more pulp in fruit.

\section{Materials and Methods}

Plant materials. Leaf material was collected from 23 lychee cultivars (Table 1), morphologically characterized, and documented at the national litchi germplasm repository, National Research Center for Litchi (NRCL), Indian Council of Agriculture Research, Muzaffarpur, India. These cultivars are commercially grown in different parts of India. Leaf material was collected from different cultivars grown in the research field of NRCL (denoted as "M"), Fruit Research Station, Punjab Agriculture University, Hoshiarpur, Punjab (denoted as " $\mathrm{H}$ "), and Yadvendra Garden, Department of Horticulture, Pinjore, Haryana (denoted as "P"). The details of the cultivars are reported in Table 1.

DNA Extraction. Genomic DNA was extracted from 100 mg of apical young leaves with DNeasy Plant Mini kit (Qiagen, Valencia, CA) following the manufacturer's protocol. The yield and quality of genomic DNA were determined using a spectrophotometer (Infinite ${ }^{\circledR}$ M200 PRO NanoQuant; Tecan, Männedorf, Switzerland). The DNA samples were visualized on ethidium bromide-stained $0.8 \%$ agarose gels.

AFLP ANALYsis. AFLP was performed using the Selective Amplification Start up Kit for Regular Plant Genomes (500 to $6000 \mathrm{Mb}$; Applied Biosystems, Foster City, CA) following the manufacturer's protocol. For each sample, $500 \mathrm{ng}$ genomic DNA was used for restriction ligation reaction. All adaptors and polymerase chain reaction primers were provided as the kit components. The AFLP reactions were performed by using three primer combinations, EcoRI-AAC/MseI-CTG, EcoRI-ACC/ $M s e I-C A T$, and EcoRI-AGC/MseI-CAT, which had been identified as polymorphic in a previous study (Ganjun et al., 2003).

Statistical analysis. Genemapper (Version 4.1; Applied Biosystems) was used for automated fragment size calling and scoring with the manufacturer's default settings. The distinct and well-resolved fragments in the size range 50 to $500 \mathrm{bp}$ were scored. The presence or absence of all fragments was confirmed manually to avoid ambiguities arising as a result of intensity differences between samples. Binary data tables showing alleles were generated and imported into tab-delimited text files.

The following statistical analyses were performed to examine the discriminatory power of the AFLP marker system: gene diversity, marker index, resolving power, and probability of identical match by chance.

Gene diversity of each allele was calculated as previously proposed (Roldan-Ruiz et al., 2000): $\mathrm{GD}_{\mathrm{i}}=2 \mathrm{f}_{\mathrm{i}}(1-\mathrm{fi})$, where $\mathrm{GD}_{\mathrm{i}}=$ gene diversity $\mathrm{i}, \mathrm{f}_{\mathrm{i}}=$ frequency of the marker bands present, and $1-\mathrm{fi}=$ frequency of marker bands absent. Marker index (MI) was calculated for each primer combination (Milbourne et al., 1997; Powell et al., 1996): $\mathrm{MI}=\mathrm{GD} \times$ EMR, where EMR is the product of the fraction of polymorphic loci and the number of polymorphic loci. Resolving power $(\mathrm{R} p)$ of each primer set was calculated as proposed by Prevost and Wilkinson (1999): $\mathrm{R} p=\Sigma \mathrm{Ib}$, where Ib (band informativeness) takes the value of $1-[2 \times|0.5-p|]$ where, $p=$ proportion of the genotypes containing the band.

Probability of identical match by chance $(\mathrm{P} i)$ of each primer combination was calculated according to Wetton et al. (1987): $\mathrm{P} i=\mathrm{X}^{\mathrm{n}}$, where $\mathrm{X}$ (similarity index between two genotypes) $=$ $2 \mathrm{~N}_{\mathrm{AB}} /\left(\mathrm{N}_{\mathrm{A}}+\mathrm{N}_{\mathrm{B}}\right), \mathrm{n}=$ average number of bands in two genotypes, $\mathrm{N}_{\mathrm{AB}}=$ number of bands present in two genotypes, $\mathrm{A}$ and $\mathrm{B}$, $\mathrm{N}_{\mathrm{A}}=$ number of bands in genotype $\mathrm{A}$, and $\mathrm{N}_{\mathrm{B}}=$ total number of bands in genotype $\mathrm{B}$. P $i$ was calculated for each possible comparison between pairs of cultivars and for each primer combination and cumulative data (Ramakrishna et al., 1994). The minimum and maximum probability of identical match by chance was also determined.

The unweighted neighbor joining algorithm cluster analysis was performed to produce dendrogram of genetic relationships among cultivars using DARwin software [Version 5.0.158 (Perrier and Jacquemoud-Collet, 2006)]. Bootstrapping analysis was carried out for the assessment of the robustness of the dendrogram topology based on coefficients of Jaccard $(\mathrm{J})$. Genetic distance among the cultivars was measured based on Nei-72 distance matrix using the NTSYSpc 2.21r software package (Rohlf, 2008). Principal coordinate analysis (PCoA) was done to establish the location of the 23 individuals in two dimensions using the NTSYSpc software.

Reproducibility of the AFLP fingerprinting was examined by repeating all the experimental steps on $17 \%$ individuals with biological replicates, as suggested previously (Bonin et al., 2004). The error rate was calculated for the biological replicates as the percentage of loci that were mismatched between the replicate pairs (Pompanon et al., 2005).

\section{Results and Discussion}

Because lychee has a narrow genetic base, assessing genetic variability and broadening genetic diversity are desirable for cultivar improvement (Huang et al., 2005; Singh et al., 2012b; Singh and Babita, 2002). Most of the Indian lychee cultivars have been introduced in India from China, as seedlings or clones, and renamed (Singh et al., 2012b). The 23 cultivars used in the present study are classified into five groups based on morphological traits (Table 1). The AFLP fingerprinting of these cultivars gave a total of 311 scorable bands. The number of fragments ranged from 78 (EcoRI-AAC $+M s e \mathrm{I}-\mathrm{CTG})$ to 129 (EcoRI-ACC + MseI-CAT) with a mean of $97.9 \%$ polymorphism (Table 2). Bands were scored by hand with reiterative approach, as described by Triplett et al. (2010), to minimize 
Table 2. Degree of polymorphism and information content for three amplified fragment length polymorphism primer combinations applied to 23 Indian lychee cultivars.

\begin{tabular}{lcccccc}
\hline Primer combination & Total bands (no.) & $\begin{array}{c}\text { Polymorphic } \\
\text { bands (\%) }\end{array}$ & $\begin{array}{c}\text { Exclusive } \\
\text { bands (no.) }\end{array}$ & Genetic diversity & Marker index & Resolving power \\
\hline EcoRI-AAC + MseI-CTG & 78 & 94.87 & 16 & $0.27 \pm 0.15$ & 19.22 & 30.43 \\
EcoRI-ACC + MseI-CAT & 129 & 100 & 31 & $0.24 \pm 0.12$ & 31.00 & 40.08 \\
EcoRI-AGC + MseI-CAT & 104 & 99.04 & 25 & $0.26 \pm 0.14$ & 26.64 & 37.21 \\
Average & 103.67 & 97.97 & 24 & $0.25 \pm 0.13$ & $25.62 \pm 5.95$ & $35.90 \pm 4.95$ \\
\hline
\end{tabular}

homoplasy effect in the data. Monomorphic and low-intensity bands were not considered in the analysis. Bands identified by the primer combinations used in this study were substantially polymorphic (97.9\%) and efficiently discriminated the Indian commercial lychee cultivars. This is in agreement with the earlier report (Ganjun et al., 2003), in which the same set of primers was used to classify 39 Chinese lychee cultivars. The AFLP fingerprinting resolved the 39 Chinese cultivars differently from the traditional classification based on the morphological traits.

In our study, AFLP fingerprints were able to discriminate the 23 Indian lychee cultivars. The GD for the markers ranged from 0.083 to 0.499 with a mean of $0.25 \pm 0.13$ per assay units. The MI of the primer sets ranged from 19 to 31 with an average of $25.62 \pm 5.95$. All the primer combinations were attributed with resolving power $(\mathrm{R} p)$ ranging from 30 to 40 (average $35.90 \pm$ 4.95). The high values of GD, MI, and Rp are in agreement with the fairly good discriminatory potential of efficient AFLP markers (Behera et al., 2008; Blignaut et al., 2013; Kesari et al., 2010; Laurentin, 2009; Sathyanarayana et al., 2011). A significant positive correlation was noticed among MI, $\mathrm{R} p$, and GD with coefficients of determination $\left(R^{2}\right)=0.991$ (MI and $\mathrm{R} p$ ), 0.924 (GD and MI), and 0.868 (GD and $\mathrm{R} p$ ). The positive correlation among GD, MI, and Rp suggests that any of the three parameters can be used to select the informative primer combination (Tatikonda et al., 2009).

The minimum, maximum, and average probability of identical match by chance per primer is given in Table 3 . Maximum value for $\mathrm{P} i$ was obtained for the primer combination EcoRI-ACC + MseI-CAT (0.3579) between cultivars Green (M) and Sarguja (M) followed by between 'Rose Scented' (M) and 'Ajhauli' (M) (0.213) with primer combination EcoRIAGC + MseI-CAT. The average $\mathrm{P} i$ for each primer was considerably less $(\leq 0.0064)$ and the total $\mathrm{P} i$ for all the three primer combinations was even less at $2.701 \times 10^{-6}$. P $i$ expresses the probability of a band present in one genotype for being present in the other genotype also (Ramakrishna et al., 1994). Significantly, low average $\mathrm{P} i$ for the marker system $(2.701 \times$ $10^{-6}$ ) suggests the capability of the marker system to distinguish identity and purity of lychee cultivars.

The Jaccard's coefficients of similarity (J), which considers matches between bands that are present (Bonin et al., 2007), is recommended for dominant markers such as AFLP (Laurentin and Karlovsky, 2007; Link et al., 1995). The dendrogram of the genetic relationship was produced by clustering the data based on J. Two distinct groups of cultivars were observed with high bootstrapping values (more than 95\%), Cluster II [Purbi (M), Calcuttia (M), and Calcuttia Late (M)], and Cluster IV [China $(\mathrm{M})$, Calcuttia $(\mathrm{H})$, Seedless Late $(\mathrm{P})$, Seedless Late $(\mathrm{H})$, and Bedana (M)] (Fig. 1). Unlike the morphological classification, cultivar China (M) was placed along with the subcluster of Bedana (M) and Seedless Late (H, P) with $100 \%$ confidence of bootstrapping (Fig. 1). The positioning of the subcluster comprising cultivars China (M) and Bedana (M)/Seedless Late $(\mathrm{H} / \mathrm{P})$ is supported by the genetic distance of less than 0.5 (Table 4), less $\mathrm{P} i\left(\mathrm{P} i=1.77 \times 10^{-23}\right)$ and similar physicochemical characteristics such as cracking, acidity, and total sugar percentage among cultivars Bedana (M)/Seedless Late $(\mathrm{H}, \mathrm{P})$ and China (M) (Singh et al., 2012b). Three cultivars [Mandraji (M), Surguja, and CHES2 (M)] were grouped in cluster I with the bootstrapping of 65\%. 'Dehradun' (M) and 'Bombai' (M) were close to Clusters I and II, respectively, with a confidence of $24 \%$ and $38 \%$ bootstrapping, respectively (Fig. 1). The positioning of 'Mandraji' (M) and 'CHES2'(M) in Cluster I and 'Purbi' (M) and 'Calcuttia' (M) in Cluster II favors the classification based on the morphological traits, which placed these cultivars together in the same Group II (Table 1).

Cluster III was compromised of four cultivars [Shahi (M), Green (M), Dehra Rose (M), Yogda (M)] with a bootstrapping support of $43 \%$ (Fig. 1). Two cultivars, Ajhauli (M) and Rose Scented (M), were separated from cluster III with a bootstrapping confidence of $34 \%$ (Fig. 1). Grouping of 'Shahi' (M), 'Green' (M), 'Dehra Rose' (M), 'Ajhauli' (M), and 'Rose Scented' (M) together agrees with the morphology-based classification (Group I, Table 1). The close genetic relation between 'Ajhauli' (M) and 'Rose Scented' (M) (genetic distance 0.116) is supported by similar physicochemical characteristics such as cracking, total soluble sugars, acidity, and total sugars (Singh et al., 2012b). The cultivars Swarn roopa (M), Longia (M), Trikolia (M), and Kasba (M) failed to group in any cluster.

The biplot from PCoA analysis of the AFLP markers supported the clustering pattern among the cultivars (Fig. 2). The AFLP analysis resolved similar clustering patterns when a representative

Table 3. Minimum, maximum and average probability of identical match by chance for three amplified fragment length polymorphism primer combinations applied to 23 Indian lychee cultivars.

\begin{tabular}{lclc}
\hline & \multicolumn{3}{c}{ Probability of identical match by chance between cultivars } \\
\cline { 2 - 4 } Primer combination & \multicolumn{1}{c}{ Minimum } & \multicolumn{1}{c}{ Maximum } & Average \\
\hline EcoRI-AAC + MseI-CTG & $5.835 \times 10^{-16}$ & 0.0744 , Seedless Late (H) and Bedana (P) & 0.00243 \\
EcoRI-ACC + MseI-CAT & $9.266 \times 10^{-56}$ & 0.3579 , Green (M) and Sarguja (M) & 0.00626 \\
EcoRI-AGC + MseI-CAT & $1.35 \times 10^{-38}$ & 0.213 , Rose Scented (M) and Ajhauli (M) & 0.00232 \\
Total & $1.74 \times 10^{-66}$ & 0.0006, Rose Scented (M) and Ajhauli (M) & $2.701 \times 10^{-6}$ \\
\hline
\end{tabular}




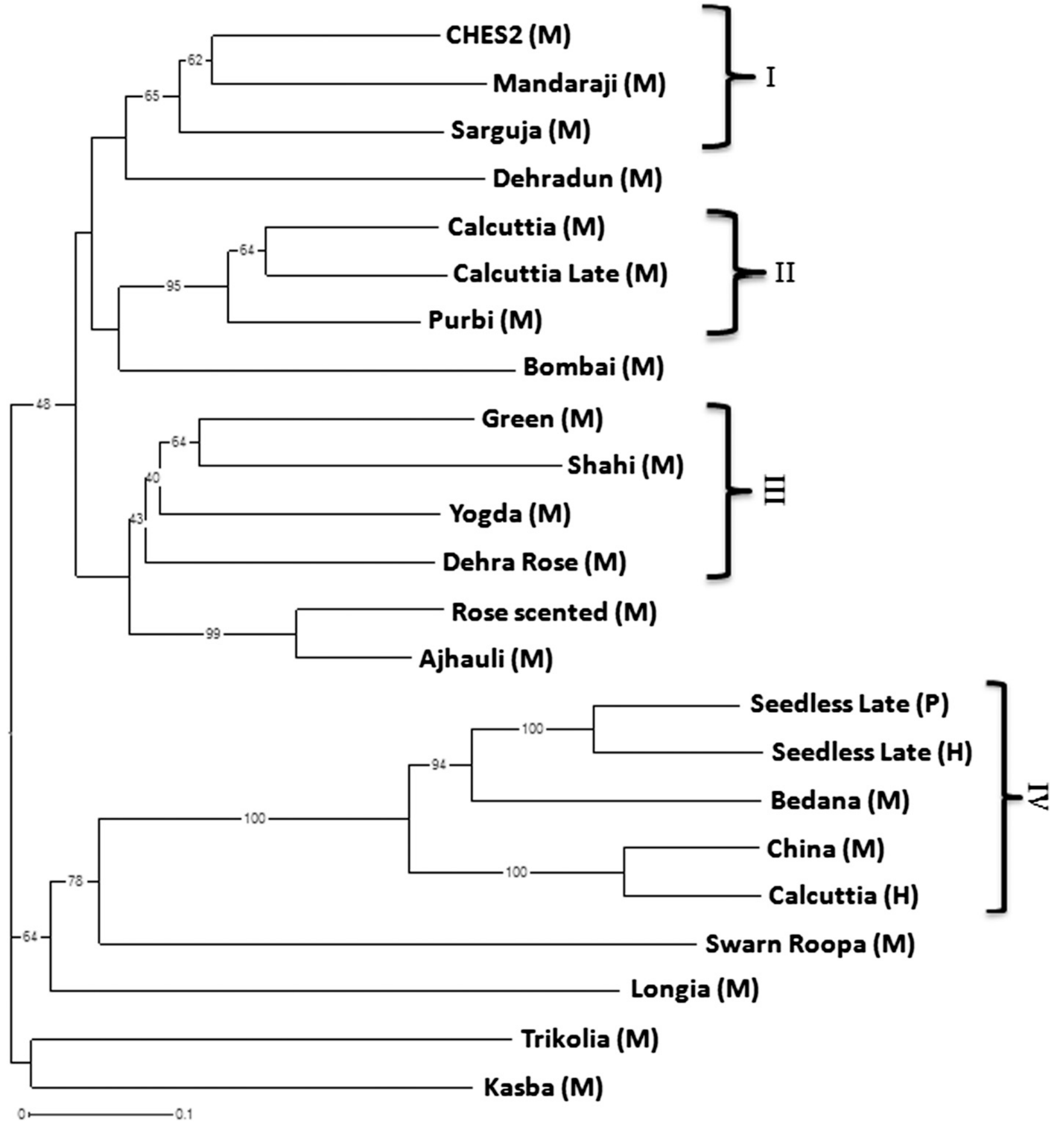

Fig. 1. Unweighted neighbor-joining tree of Indian lychee cultivars based on Jaccard's coefficient using 306 polymorphic amplified fragment length polymorphism (AFLP) markers. Bootstrapping values, involving 1000 repetitions, was carried out to determine the robustness of the dendrogram. Bootstrapping values are indicated for clusters with values equal or higher than $40 \%$. The scale represents Jaccard's similarity coefficient [DARwin Version 5.0.158 (Perrier and Jacquemoud-Collet, 2006)]; M = National Research Center for Litchi (NRCL), Muzaffarpur, Bihar, India; H = Fruit Research Station (FRS), Hoshiarpur, Punjab, India; $\mathrm{P}=$ horticulture plot, Yadvendra Garden (YG), Pinjore, Haryana, India.

data comprising biological replicates of $17 \%$ cultivars was analyzed (Fig. 3). The AFLP profiling revealed $2 \%$ to $5 \%$ differences between the biological replicate pairs (data not shown).

In a recent study, molecular polymorphism was characterized among Lychee accessions by using 11 microsatellite (SSR) loci (Madhou et al., 2013). Although the SSR markers showed considerably high power of resolution, of eight Indian cultivars, six were undistinguishable ('Bengal $2 \mathrm{~m}$ ', 'Calcuttia Late 5m', 'Calcutta 10r', 'Bengali 12r', 'Saharanpur 15r', 'Bengal 22r', 'Rose Scented 32r', 'Mujjafarpur 35r', and 'Bengal 3s'). 


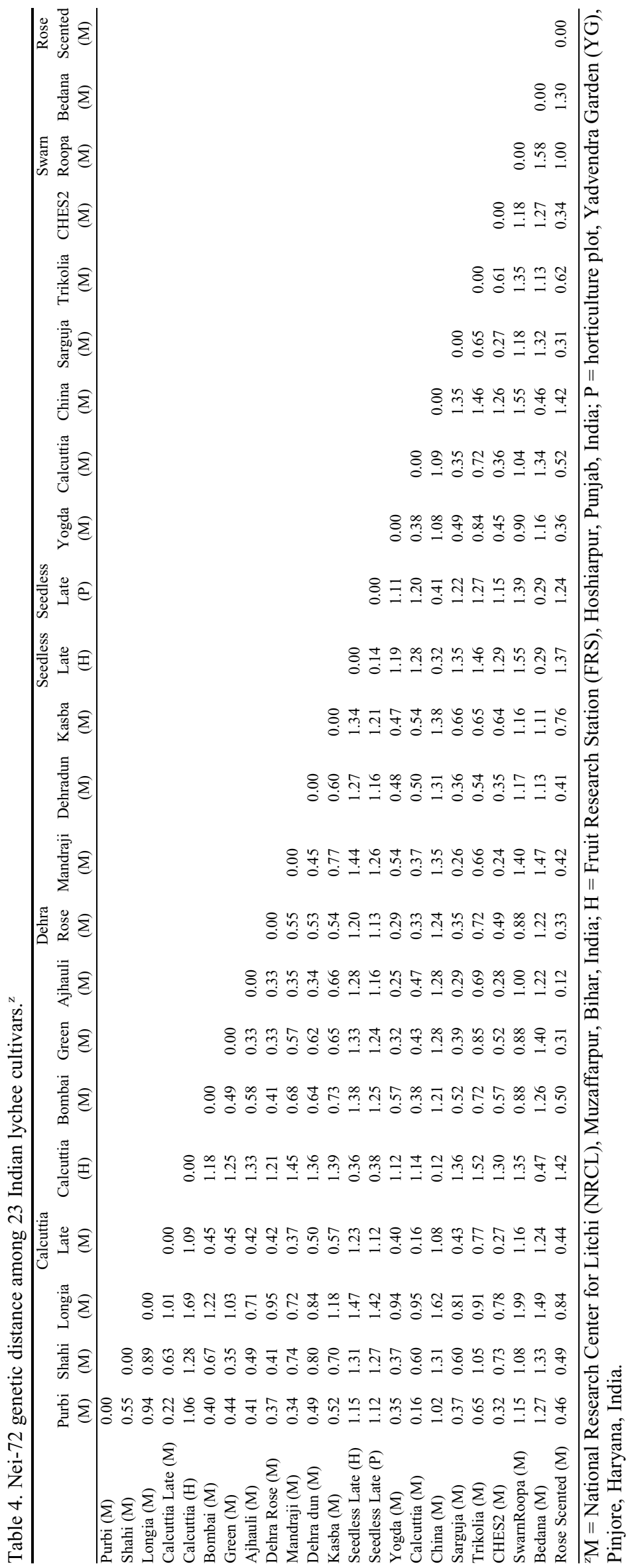




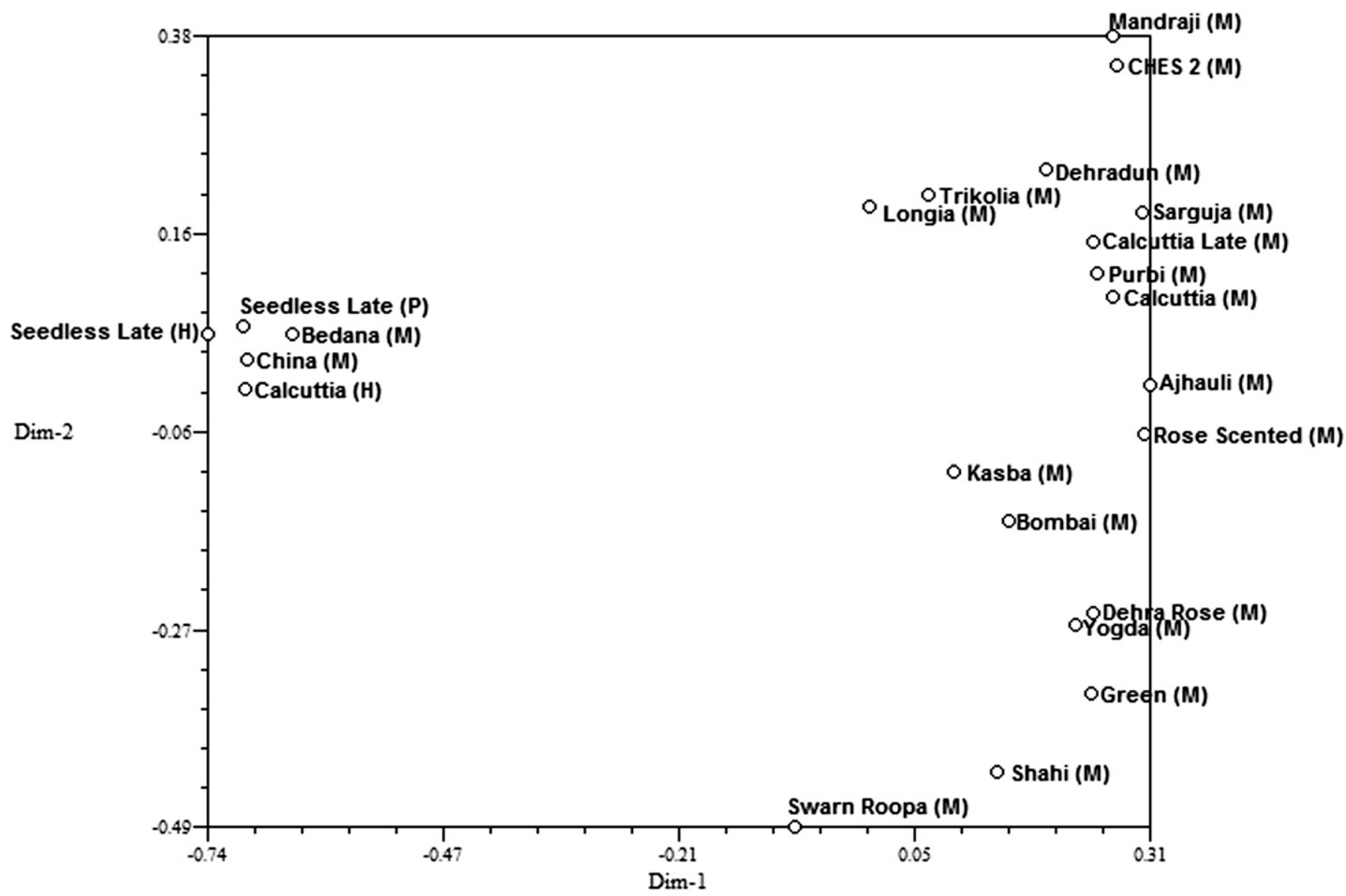

Fig. 2. Two-dimensional graph from the principal coordination analysis of 306 amplified fragment length polymorphism (AFLP) markers of lychee cultivars [DARwin Version 5.0.158 (Perrier and Jacquemoud-Collet, 2006)]; $\mathrm{M}=$ National Research Center for Litchi (NRCL), Muzaffarpur, Bihar, India; H $=$ Fruit Research Station (FRS), Hoshiarpur, Punjab, India; P = horticulture plot, Yadvendra Garden (YG), Pinjore, Haryana, India.

Among the six unresolved cultivars, three (Calcuttia Late, Calcutta, and Rose Scented) were common with our study. Our AFLP marker analysis was able to differentiate 'Rose Scented' from 'Calcuttia' and 'Calcuttia Late' by a genetic distance of 0.521 and 0.444 , respectively, unlike being unresolved by SSR fingerprinting. This could be suggestive of higher resolving power of the AFLP markers. In ISSR marker analysis, 'Bedana' was placed far removed from 'Late Seedless' and 'Seedless' (Degani et al., 2003). In the present study, AFLP fingerprinting identified close genetic similarity between the small-seeded cultivars, Bedana and Seedless Late, which agrees with morphological resemblance between them.

The AFLP marker system discriminated 'Dehra Rose' (M) from 'Dehradun' (M), which are often mistaken for each other (Singh et al., 2012b). This result coincides with the findings of ISSR marker analysis (Degani et al., 2003). This suggests that the morphological characterization can be corrected by molecular studies for identifying the two cultivars in different parts of India.

The cluster analysis revealed considerable genetic similarity between 'Ajhauli' (M) and 'Rose Scented' (M) and 'Purbi' (M) and 'Calcuttia' (M) (Fig. 1) with the Nei-72 genetic distance of 0.116 and 0.157 , respectively (Table 4 ). The cultivar known as Calcuttia (H) grown in the Fruit Research Station (FRS), Hosiarpur, Punjab, was genetically very similar to China (M) grown in NRCL, Muzaffarpur (Fig. 1; Table 4), suggesting that 'Calcuttia' $(\mathrm{H})$ growing in FRS could be the same clone as
China (M). The genetic distance between 'Bedana' (M)/'Seedless Late' $(\mathrm{P}, \mathrm{H})$ and 'Calcuttia' $(\mathrm{H})$ being similar as that of 'Bedana' (M)/'Seedless Late' (P, H) and 'China' (M) further supports the speculation (Table 4). Thus, the genotypic fingerprinting with the primer combinations used in the study could detect and resolve the instances of "same cultivar with different names" in the case of lychee.

Substantial genetic similarity was observed between 'Calcuttia Late' (M) and 'Calcuttia' (M) (Fig. 1). A similar result was obtained in the microsatellite markers-based study (Madhou et al., 2013). The 'Seedless Late' (H, P) plants growing in the Punjab and Haryana region were grouped with 'Bedana' (M) of the Bihar region (Fig. 1; Table 4). The cultivars, Longia (M), Swarnroopa (M), and China (M), were most distantly related (Nei-72 genetic distance was more than 1.5) with one another (Fig. 1; Table 4). The AFLP characterization agrees with the placement of 'Kasba' (M) and 'Longia' (M) in distinctly separate groups on the basis of morphological traits (Table 1; Fig. 1). In morphological classification, 'Swarnroopa' was placed with 'Bedana', whereas in the AFLP clustering pattern, it was separated from the 'Bedana' group by a confidence level of $78 \%$ bootstrapping (Fig. 1).

The number of bands per genotype ranged from 56 for 'Surguja' (M) to 119 for 'Calcuttia' (H). Seventy-two unique bands were observed in the 23 cultivars. The cultivar Swarnroopa $(\mathrm{M})$ had a maximum number of exclusive bands (14) 


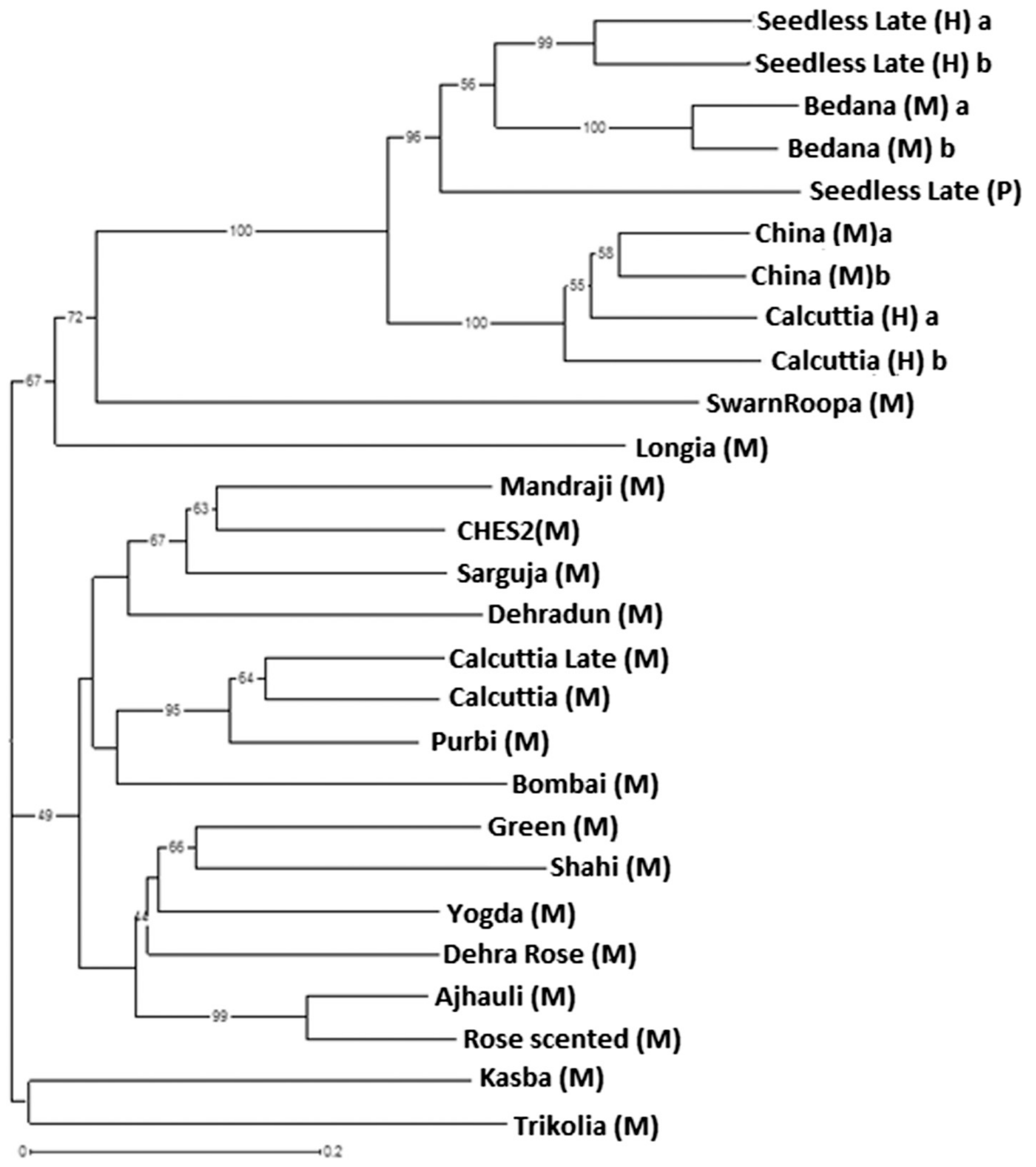

Fig. 3. Unweighted neighbor-joining tree of 23 Indian litchi cultivars, with replicates of four cultivars, based on Jaccard's coefficient using 350 polymorphic amplified fragment length polymorphism (AFLP) markers. The replicates are: 'Seedless Late' (A-B), 'Bedana' (A-B), 'China' (A-B), and 'Calcuttia' (A-B). Bootstrapping values, involving 1000 repetitions, was carried out to determine the robustness of the dendrogram. Bootstrapping values are indicated for clusters with values equal or higher than $40 \%$. The scale represents Jaccard's similarity coefficient [DARwin Version 5.0.158 (Perrier and Jacquemoud-Collet, 2006)]; $\mathrm{M}=$ National Research Center for Litchi (NRCL), Muzaffarpur, Bihar, India; H = Fruit Research Station (FRS), Hoshiarpur, Punjab, India; P = horticulture plot, Yadvendra Garden (YG), Pinjore, Haryana, India. 

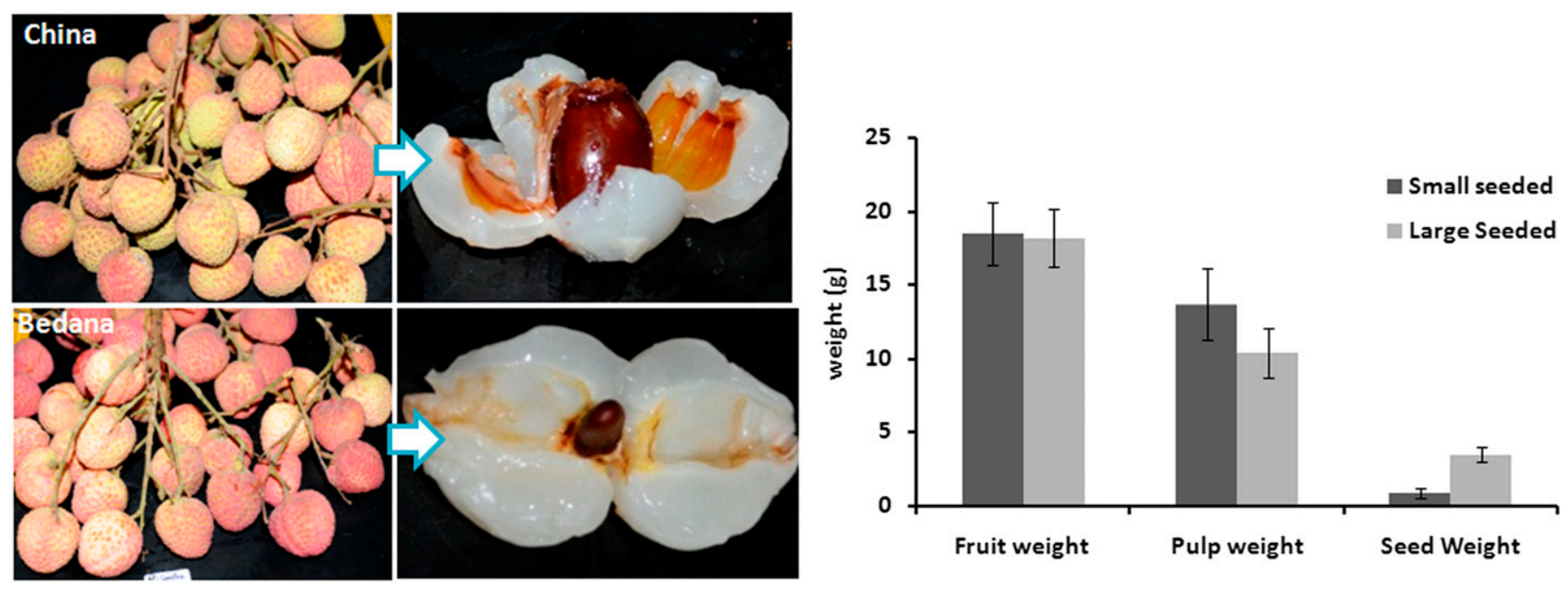

Fig. 4. (A) Fruit of small- and bold-seeded Indian Lychee cultivars. The small-seeded cultivar (Bedana) contains more pulp and small seed in fruit as compared with the bold-seeded cultivar (China). (B) Comparison of average fruit weight, pulp weight, and seed weight of small- and bold-seeded cultivars. The error bars indicate the SE in 75 fruit harvested from three different plants ( 25 fruit from each plant) of each genotype.

Table 5. Unique bands identified exclusively in small-seeded lychee cultivars: the size of unique bands, genetic diversity and band informativeness of the amplified fragment length polymorphism primer combinations.

\begin{tabular}{|c|c|c|c|c|c|}
\hline Primer & Band size (bp) & $\begin{array}{l}\text { Band in small-seeded } \\
\text { genotypes }\end{array}$ & $\begin{array}{c}\text { Band in bold-seeded } \\
\text { genotypes }\end{array}$ & Genetic diversity & Band informativeness \\
\hline EcoRI AAC/MseI CTG & 126 & Present & Absent & 0.30178 & 0.3964 \\
\hline EcoRI ACC/MseI CAT & 106 & Present & Absent & & \\
\hline EcoRI ACC/MseI CAT & 202 & Present & Absent & & \\
\hline EcoRI ACC/MseI CAT & 210 & Present & Absent & & \\
\hline
\end{tabular}

followed by 'Longia' (M) (12) and 'Bedana' (M) (six), whereas 'Yogda' (M) and 'Calcuttia' (M) did not show unique bands.

Exclusive fingerprints were identified in the cultivars having small seed and large pulp in the fruit in comparison with the bold-seeded cultivars (Fig. 4). Five AFLP fragments unique to the small-seeded cultivars were noticed in case of 'Bedana' (M), 'Seedless Late' (H), and 'Seedless Late' (P) (Table 5). Of these, one unique fragment was obtained by using EcoRI AAC/ $M s e$ I CTG and the other four by EcoRI ACC/MseI CAT primer pairs. The three cultivars were not genotypically identical. The AFLP profile showed $76 \%$ similarity between cultivars Seedless Late (P, H) and Bedana (M) (Supplemental Table 1). The genotypic difference of $24 \%$ is significant because the replicates, for example the duplicate samples of 'Bedana' (M) and 'Seedless Late' $(\mathrm{H})$, showed $97 \%$ and 95\% similarity, respectively (data not shown). The results suggest the possibility of association of the five unique bands with the cultivars bearing small-seeded fruit.

The unique bands (an average of 24 per primer combination) may be of further use in the development of sequence tagged site markers (Laurentin and Karlovsky, 2007). Exclusive bands detected in small-seeded cultivars by the two primer combinations could be potential markers for the genotypes bearing fruit with small seed size and more pulp.

The instances of synonymies and homonymies are major limitations in breeding and germplasm management in lychee (Madhou et al., 2013). Our study validates informativeness of the AFLP markers in cultivar identification and genetic studies.
The AFLP fingerprinting and genetic relatedness presented in the study are useful for unequivocal identification of lychee cultivars, selecting appropriate accessions for cultivar improvement, germplasm management, and deciding suitable conservation strategies.

\section{Literature cited}

Anuntalabhochai, R., R. Chundet, J. Chiangda, and P. Apavatjrut. 2002. Genetic diversity within lychee (Litchi chinensis Sonn.) based on RAPD analysis. Acta Hort. 575:253-259.

Aradhya, M.K., F.T. Zee, and R.M. Manshardt. 1995. Isozyme variation in lychee (Litchi chinensis Sonn.). Sci. Hort. 63:21-35.

Barbosa, A.M.M., I.O. Geraldi, L.L. Benchimol, A.A.F. Garcia, C.L. Souza, Jr., and A.P. Souza. 2003. Relationship of intra- and interpopulation tropical maize single cross hybrid performance and genetic distances computed from AFLP and SSR markers. Euphytica 130:87-99.

Behera, T.K., A.B. Gaikward, A.K. Singh, and J.E. Staub. 2008. Relative efficiency of DNA markers (RAPD, ISSR and AFLP) in detecting genetic diversity of bitter gourd (Momordica charantia L.). J. Sci. Food Agr. 88:733-737.

Belaj, A., Z. Satovic, G. Cipriani, L. Baldoni, R. Testolin, L. Rallo, and I. Trujillo. 2003. Comparative study of the discriminating capacity of RAPD, AFLP and SSR markers and of their effectiveness in establishing genetic relationships in olive. Theor. Appl. Genet. 107:736-744.

Blignaut, M., A.G. Ellis, and J.J. Le Roux. 2013. Towards a transferable and cost-effective plant AFLP protocol. PLoS One 8:e61704.

Bonin, A., E. Bellemain, P.B. Eidesen, F. Pompanon, C. Brochmann, and P. Taberlet. 2004. How to track and assess genotyping errors in population genetics studies. Mol. Ecol. 13:3261-3273. 
Bonin, A., D. Ehrich, and S. Manel. 2007. Statistical analysis of amplified fragment length polymorphism data: A toolbox for molecular ecologists and evolutionists. Mol. Ecol. 16:37373758.

Campbell, D., P. Duchesne, and L. Bernatchez. 2003. AFLP utility for population assignment studies: Analytical investigation and empirical comparison with microsatellites. Mol. Ecol. 12:1979-1991.

Chundet, R., R.W. Cutler, M. Tasanon, and S. Anuntalabhochai. 2007. Hybrid detection in lychee (Litchi chinensis Sonn.) cultivars using HAT-RAPD markers. Sci. Asia 33:307-311.

Degani, C., A. Beiles, R. El-Batsri, M. Goren, and S. Gazit. 1995. Identifying lychee cultivars by isozyme analysis. J. Amer. Soc. Hort. Sci. 120:307-312.

Degani, C., J. Deng, A. Beiles, R. El-Batsri, M. Goren, and S. Gazit. 2003. Identifying lychee (Litchi chinensis Sonn.) cultivars and their genetic relationships using inter simple sequence repeat (ISSR) markers. J. Amer. Soc. Hort. Sci. 128:838-845.

Diczbalis, Y. 2011. Farm and forestry production and marketing profile for lychee (Litchi chinensis). Specialty crops for pacific island agroforestry. 21 Apr. 2014. <http://www.clshade.net/agroforestry/scps/ Lychee_specialty_crop.pdf $>$.

Dwivedi, A.K. and S.K. Mitra. 1996. Divergence analysis of litchi (Litchi chinensis sonn.) cultivars grown in West Bengal. Indian J. Genet. Plant Breed. 56:486-489.

Ganjun, Y., H. Heqiang, C. Dacheng, H. Ziran, C. Changhd, and Q. Yanping. 2003. Studies on genetic relationship among litchi varieties by using AFLP. Acta Hort. Sinica 30:399-403.

Gerber, S., S. Mariette, R. Streiff, C. Bodenes, and A. Kremer. 2000. Comparison of microsatellites and amplified fragment length polymorphism markers for parentage analysis. Mol. Ecol. 9:10371048.

Guo, Y.P., J. Saukel, R. Mittermayr, and F. Ehrendorfer. 2005. AFLP analyses demonstrate genetic divergence, hybridization, and multiple polyploidization in the evolution of Achillea (AsteraceaeAnthemideae). New Phytol. 166:273-289.

Huang, X., S. Subhadrabandhu, S.K. Mitra, R. Benarie, and R.A. Stern. 2005. Litchi and logan, p. 1-23. In: Menzel, C.M. and G.K. Waite (eds.). Origin, history, production and processing. Cromwell Press, Trowbridge, UK.

Jones, C.J., K.J. Edwards, S. Castaglione, M.O. Winfield, F. Sala, C. van de Wiel, G. Bredemeijer, B. Vosman, M. Matthes, A. Daly, R. Brettschneider, P. Bettini, M. Buiatti, E. Maestri, A. Malcevschi, N. Marmiroli, R. Aert, G. Volckaert, J. Rueda, R. Linacero, A. Vazquez, and A. Karp. 1997. Reproducibility testing of RAPD, AFLP and SSR markers in plants by a network of European laboratories. Mol. Breed. 3:381-390.

Kesari, V., V.M. Sathyanarayana, A. Parida, and L. Rangan. 2010. Molecular marker-based characterization in candidate plus trees of Pongamia pinnata, a potential biodiesel legume. AoB Plants plq017.

Kremer, A., H. Caron, S. Cavers, N. Colpaert, G. Gheysen, R. Gribel, M. Lemes, A.J. Lowe, R. Margis, C. Navarro, and F. Salgueiro. 2005. Monitoring genetic diversity in tropical trees with multilocus dominant markers. Hereditary 95:274-280.

Kumar, M., M. Gupta, D. Shrivastava, M. Prasad, U.S. Prasad, and N. BhallaSarin. 2010. Genetic relatedness among Indian litchi accessions (Litchi chinensis Sonn.) by RAPD markers. Intl. J. Agr. Biol. 5:805-815.

Laurentin, H. 2009. Data analysis for molecular characterization of plant genetic resources. Genet. Resources Crop Evol. 56:277-292. Laurentin, H. and P. Karlovsky. 2007. AFLP fingerprinting of sesame (Sesamum indicum L.) cultivars: Identification, genetic relationship and comparison of AFLP informativeness parameters. Genet. Resources Crop Evol. 54:1437-1446.

Link, W., C. Dixkens, M. Singh, M. Schwall, and A.E. Melchinger. 1995. Genetic diversity in European and Mediterranean Faba bean germplasm revealed by RAPD markers. Theor. Appl. Genet. 90:2732.
Madhou, M., F. Normand, T. Bahorun, and J.I. Hormaza. 2013. Fingerprinting and analysis of genetic diversity of litchi (Litchi chinensis Sonn.) accessions from different germplasm collections using microsatellite markers. Tree Genet. Genomes 9:387-396.

Mariette, S., V.L. Corre, F. Austerlitz, and A. Kremer. 2002. Sampling within the genome for measuring within-population diversity: Tradeoffs between markers. Mol. Ecol. 11:1145-1156.

Meudt, H.M. and A.C. Clarke. 2007. Almost forgotten or latest practice? AFLP applications, analyses and advances. Trends Plant Sci. 12:106-117.

Milbourne, D., R. Meyer, J. Bradshaw, E. Baird, N. Bonar, J. Provan, W. Powell, and R. Waugh. 1997. Comparison of PCR-based marker systems for the analysis of genetic relationships in cultivated potato. Mol. Breed. 3:127-136.

Mingfang, L., Z. Xueqing, Z. Yongqiang, W. Xiangshe, L. Suyu, L. Lei, and W. Xingrong. 2006. Development and characterization of SSR markers in lychee (Litchi chinensis). Mol. Ecol. Res. 6:1205-1207.

National Horticulture Board. 2013. Statistics, area and production statistics, 2nd advance estimate of area and production of horticulture crops (2013-2014). 21 Apr. 2014. <http://nhb.gov.in/area\%20_ production.html>.

National Research Centre for Litchi. 2011. Catalogue of litchi germplasm. Natl. Res. Ctr. Litchi Tech. Bul. AICRP(STF)2011(1).

Perrier, X. and J.P. Jacquemoud-Collet. 2006. DARwin software. 9 Apr. 2014. $<$ http://darwin.cirad.fr/>.

Perseguini, J.M.K.C., A.F. Chioratto, M.I. Zucchi, C.A. Colombo, S.A.M. Carbonell, J.M.C. Mondego, R. Gazaffi, A.A.F. Garcia, T. Campos, A.P. Souza, and L.B. Rubiano. 2011. Genetic diversity in cultivated carioca common beans based on molecular marker analysis. Genet. Mol. Biol. 34:88-102.

Pompanon, F., A. Bonin, E. Bellemain, and P. Taberlet. 2005. Genotyping errors: Causes, consequences and solutions. Nat. Rev. Genet. 6:847-859.

Powell, W., M. Margenta, C. Andre, M. Hanfrey, J. Vogel, S. Tingey, and A. Rafalsky. 1996. The utility of RFLP, RAPD, AFLP and SSR (microsatellite) markers for germplasm analysis. Mol. Breed. 2:225238.

Prevost, A. and M. Wilkinson. 1999. A new system of comparing PCR primers applied to ISSR fingerprinting of potato cultivars. Theor. Appl. Genet. 98:107-112.

Ramakrishna, W., M. Lagu, V. Gupta, and P. Ranjekar. 1994. DNA fingerprinting in rice using oligonucleotide probes specific for simple repetitive DNA sequences. Theor. Appl. Genet. 88:402406.

Rohlf, F.J. 2008. NTSYS-pc: Numerical taxonomy system, version 2.20. Exeter Publ., Setauket, NY.

Roldan-Ruiz, I., J. Dendauw, E. VanBockstaele, A. Depicker, and M. De Loose. 2000. AFLP markers reveal high polymorphic rates in rye grasses (Lolium spp.). Mol. Breed. 6:125-134.

Sathyanarayana, N., M. Leelambika, S. Mahesh, and M. Jaheer. 2011. AFLP assessment of genetic diversity among Indian Mucuna accessions. Physiol. Mol. Plant Pathol. 17:171-180.

Schlotterer, C. 2004. The evolution of molecular markers-Just a matter of fashion? Nat. Rev. Genet. 5:63-69.

Sima, C.H., M.C. Mahania, C.Y. Choonga, and I. Salma. 2005. Transferability of SSR markers from lychee (Litchi chinensis Sonn.) to pulasan (Nephelium ramboutan-ake L.). Fruit 60:379-385.

Singh, A., S.D. Pandey, and V. Nath. 2012a. The world litchi cultivars. Natl. Res. Ctr. Litchi Tech. Bul. NRCL/TB/007.

Singh, G., V. Nath, S.D. Pandey, P.K. Ray, and H.S. Singh. 2012b. The litchi, p. 18-37. In: Cultivars and genetic enhancement. FAO, Rome, Italy.

Singh, H.S. and S. Babita. 2002. Lychee production in the Asia-Pacific region, p. 55-77. In: Papademetriou, M.K. and F.J. Dent (eds.). Lychee production in India. FAO/RAP Publ., Bangkok, Thailand.

Sunnucks, P. 2000. Efficient genetic markers for population biology. Trends Ecol. Evol. 15:199-203. 
Tatikonda, L., S.P. Wani, S. Kannana, N. Beerelli, T.K. Sreedevi, D.A. Hoisingtona, P. Devi, and R.K. Varshney. 2009. AFLPbased molecular characterization of an elite germplasm collection of Jatropha curcas L., a biofuel plant. Plant Sci. 176:505-513.

Tongpamnak, P., A. Patanatara, P. Srinives, and C. Babprasert. 2002. Determination of genetic diversity and relationships among Thai litchi accessions by RAPD and AFLP markers. Kasetsart. J. Natural Sci. 36:370-380.

Triplett, J.K., K.A. Oltrogge, and L.G. Clark. 2010. Phylogenetic relationships and natural hybridization among the North American woody bamboos (Poaceae: Bambusoideae: Arundinaria). Amer. J. Bot. 97:471-492.
Viruel, M.A. and J.I. Hormaza. 2004. Development, characterization and variability analysis of microsatellites in lychee (Litchi chinensis Sonn. Sapindaceae). Theor. Appl. Genet. 108:896-902.

Vuylsteke, M., J. Peleman, and M.J.T. Van Eijk. 2007. AFLP technology for DNA fingerprinting. Nat. Protoc. 2:1387-1398.

Wetton, J., R. Carter, D. Parkin, and D. Walters. 1987. Demographic study of a wild house sparrow population by DNA fingerprinting. Nature 327:147-149.

Woodhead, M., J. Russel, J. Squirrel, P.M. Hollingsworth, K. Mackenzie, M. Gibby, and W. Powell. 2005. Comparative analysis of population genetic structure in Athyrium distentifolium (Pteridophyta) using AFLPs and SSRs from anonymous and transcribed gene regions. Mol. Ecol. 14:1681-1695. 


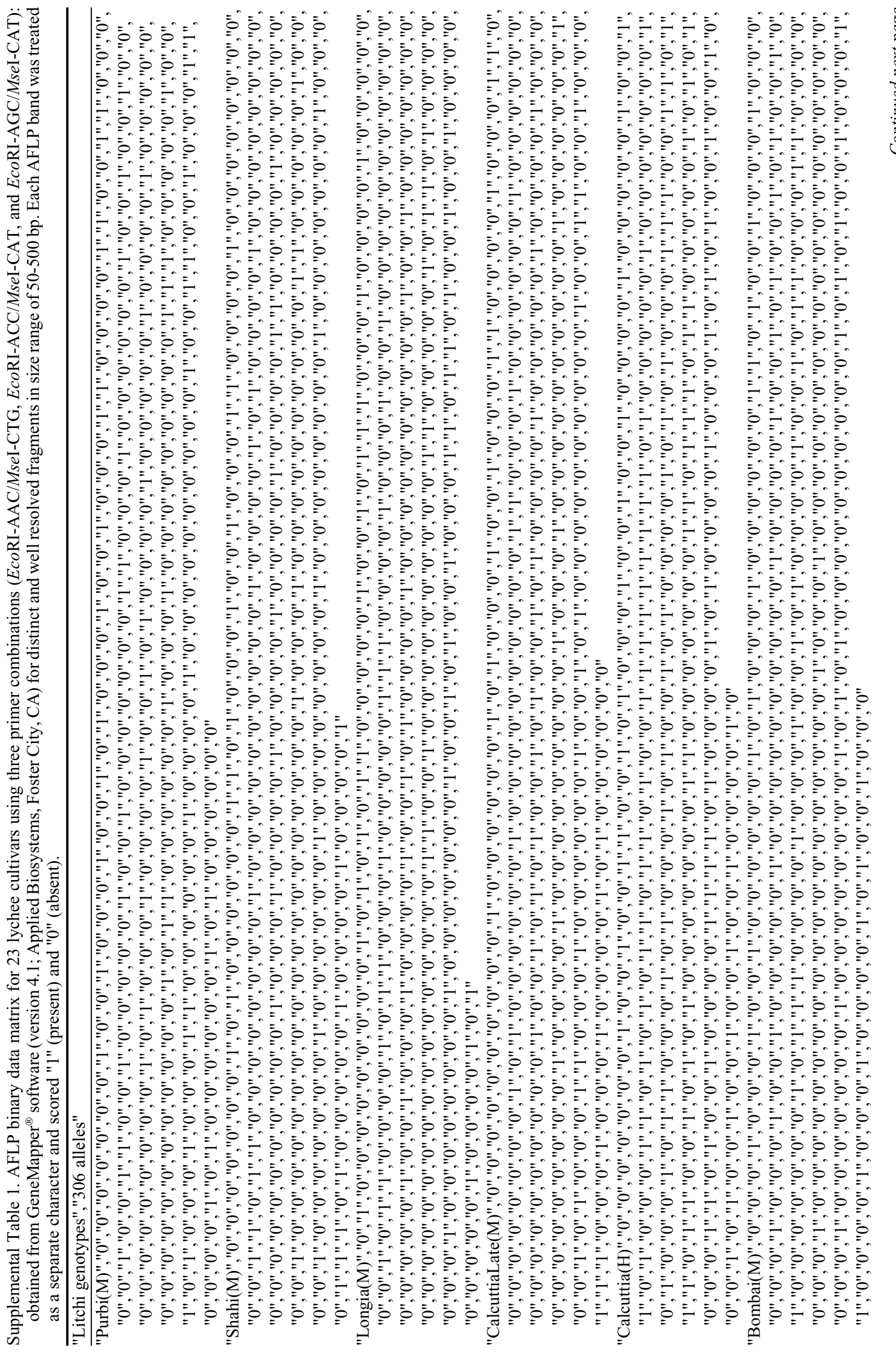




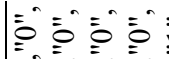

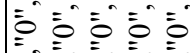

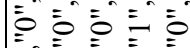

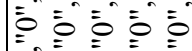

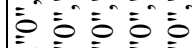

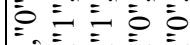

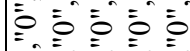
$00 \overline{0}=0$ $\bar{O} \equiv \bar{O}$ $0 \overline{0}=0$

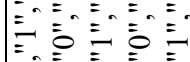

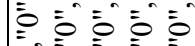

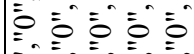

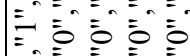

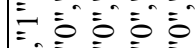

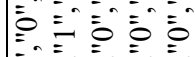

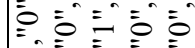

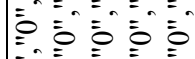

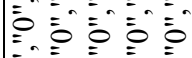

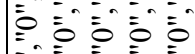

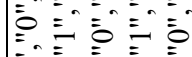

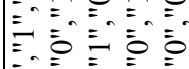

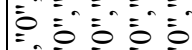

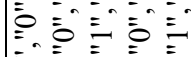

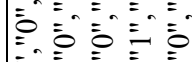

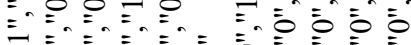

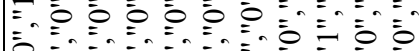
Ō”

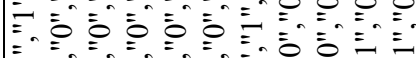

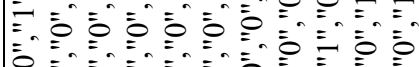

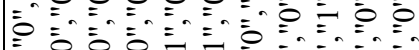

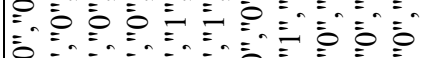

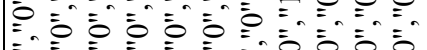

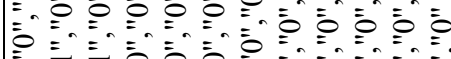

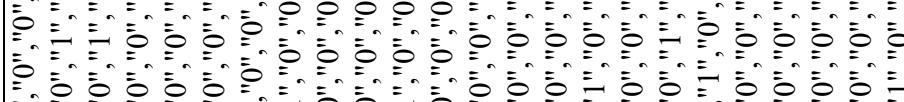
Oڤ

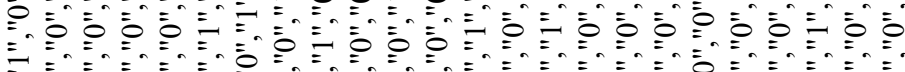

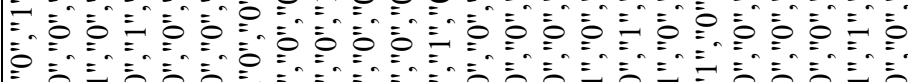

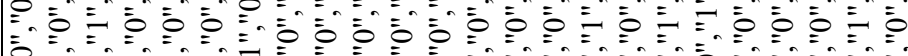

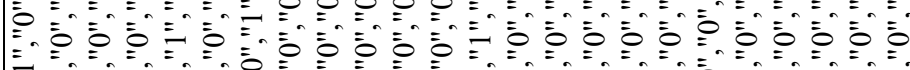

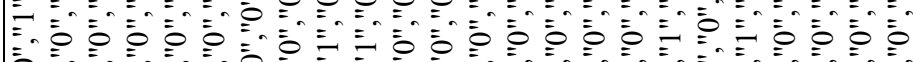

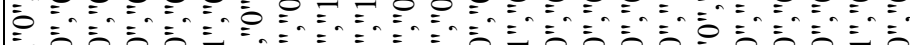

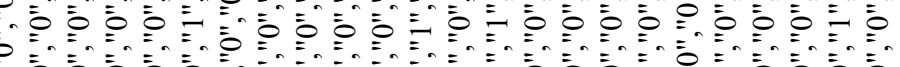

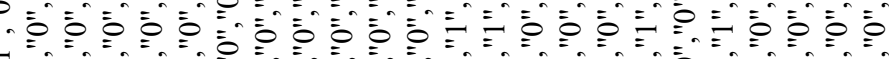
$=$

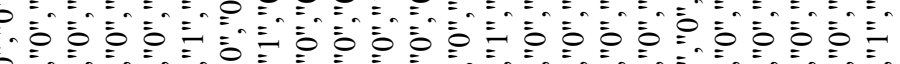

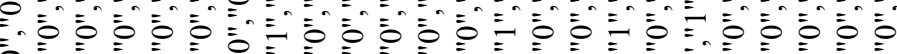

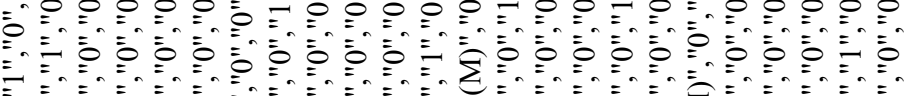

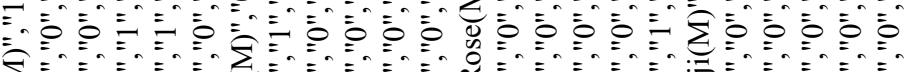

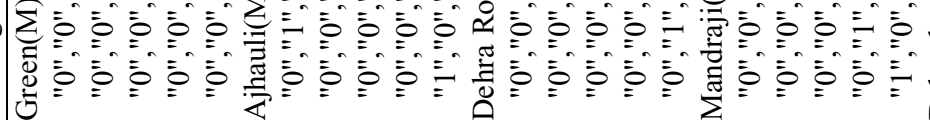

$000 \overline{0} \equiv$

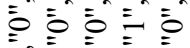

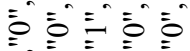

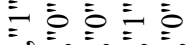

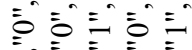
$0 \bar{O}=0$

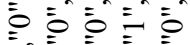
$\fallingdotseq \equiv \equiv \bar{\equiv} \equiv$ $=0$ $\overline{0} \equiv \bar{D} \equiv$ $\bar{O} \bar{O} \equiv \bar{O}$ $\overline{0} \overline{0} \equiv \overline{0} \equiv$

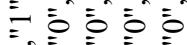

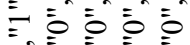
$\bar{O} \equiv \bar{\equiv} \equiv$

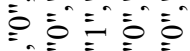

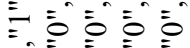
ڤ”⿱ $\fallingdotseq 0 \equiv \bar{O} \equiv \overline{0} \equiv$

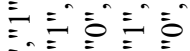

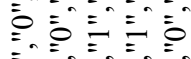
○”

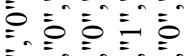

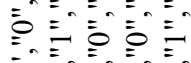

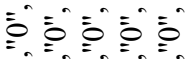

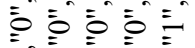

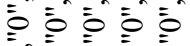

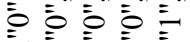
势 $=000$ $\bar{O} \bar{O} \equiv \bar{O} \equiv$ $\bar{O} \equiv \bar{O} \bar{O}$ $\bar{O} \bar{O} \equiv \bar{O}$

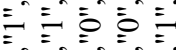

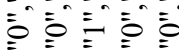
$\bar{O} \equiv \bar{O} \equiv$

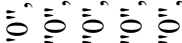

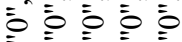

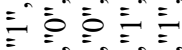

政 $\bar{O}=0$

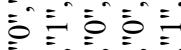
$\bar{O} \equiv \bar{O}$

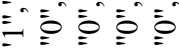

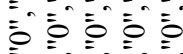

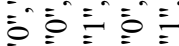

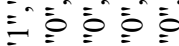
$\overline{0}=0$ $\overline{0}$

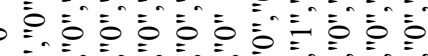

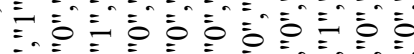

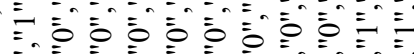

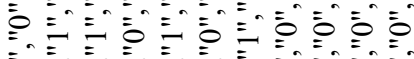

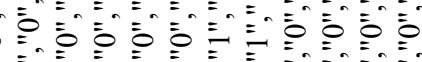

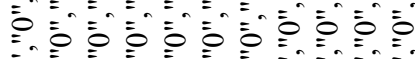

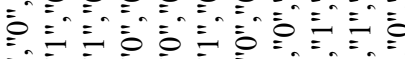

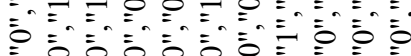
$=0$

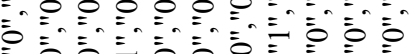
$\cong \equiv$

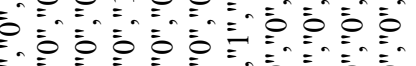

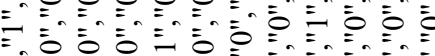

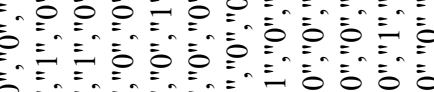

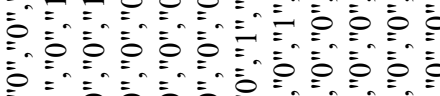

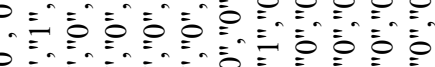

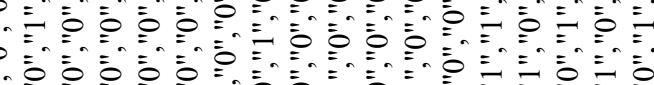

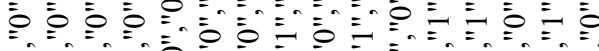
$=0000000$

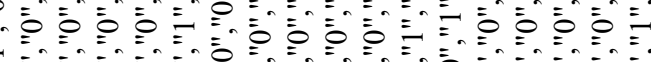
$=0$

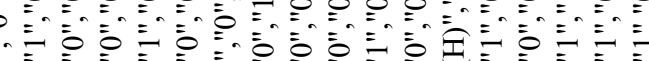

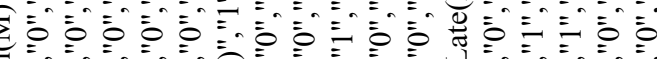

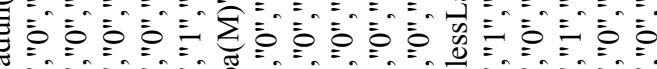

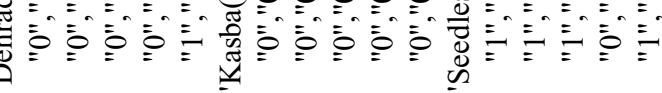




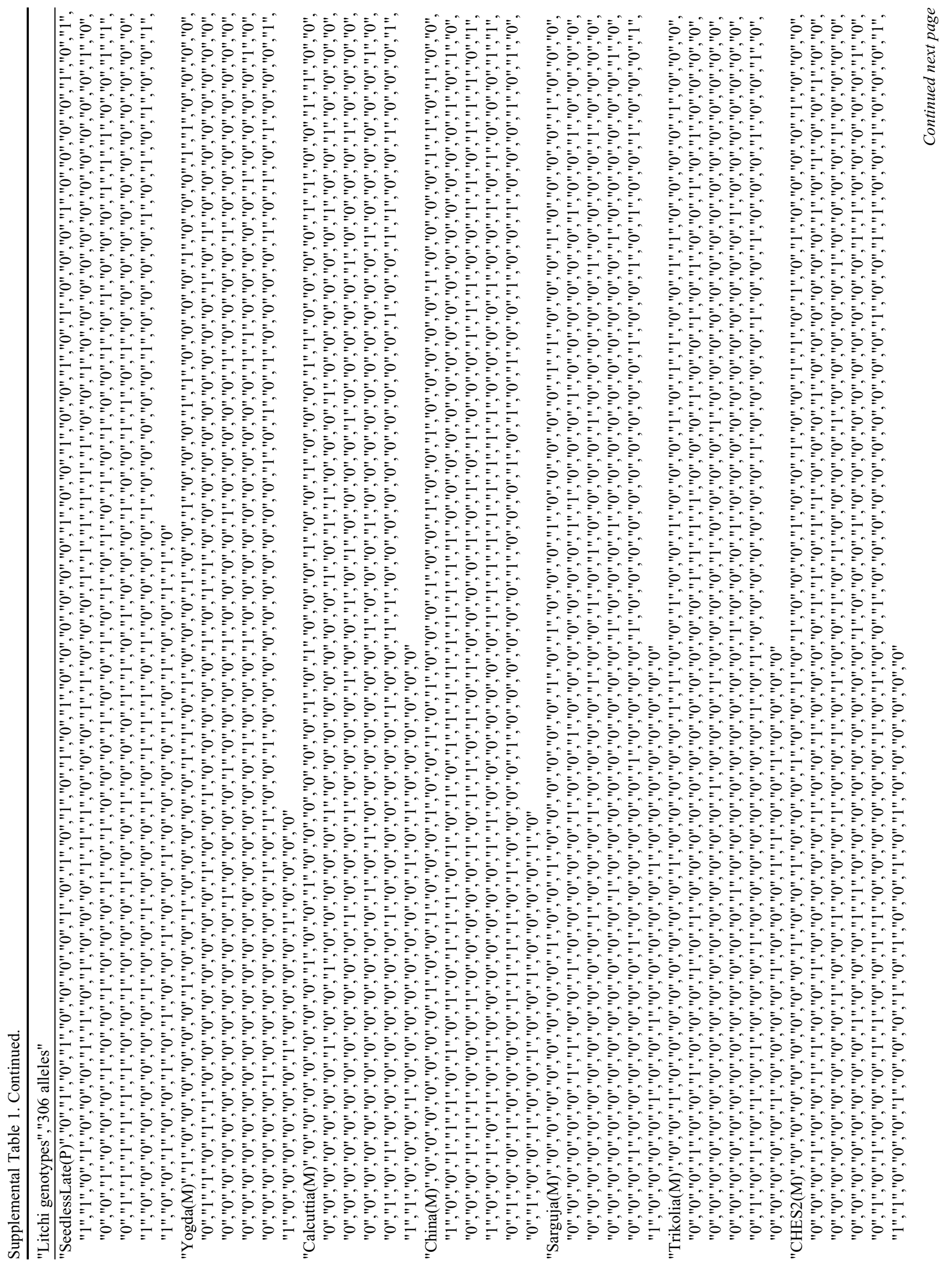




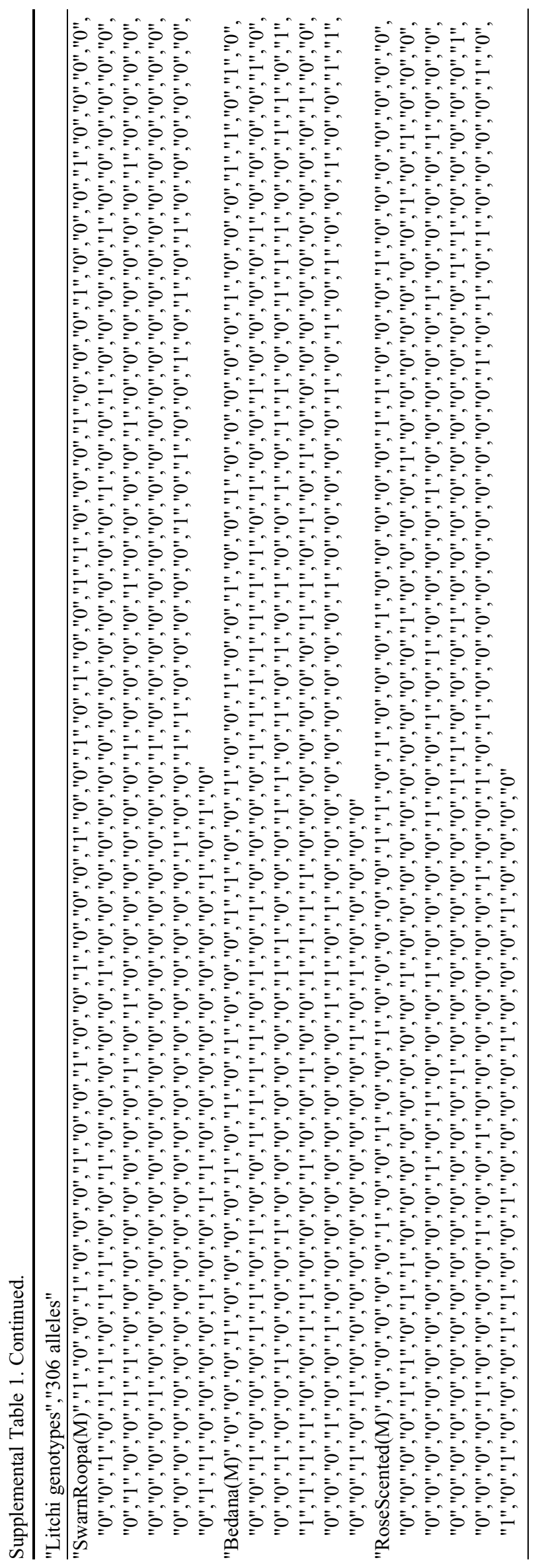

